\title{
The generation of oligodendroglial cells is preserved in the rostral migratory stream during aging
}

\author{
Vivian Capilla-Gonzalez ${ }^{1}$, Arantxa Cebrian-Silla ${ }^{2}$, Hugo Guerrero-Cazares ${ }^{1}$, Jose M. Garcia-Verdugo ${ }^{2 *}$ \\ and Alfredo Quiñones-Hinojosa ${ }^{1}{ }^{*}$
}

'Brain Tumor Stem Cell Laboratory, Department of Neurosurgery, Johns Hopkins School of Medicine, Baltimore, MD, USA
2 Laboratory of Comparative Neurobiology, Instituto Cavanilles de Biodiversidad y Biologia Evolutiva, University of Valencia, CIBERNED, Paterna, Valencia, Spain

\section{Edited by:}

Oscar Gonzalez-Perez, Univerisdad

de Colima, Mexico

Reviewed by:

Jie Zhang, University of Texas

Health Science Center at San

Antonio, USA

Rebecca Ihrie, Vanderbilt University

Medical Center, USA

\section{*Correspondence:}

Jose M. Garcia-Verdugo, Laboratory of Comparative Neurobiology, Instituto Cavanilles de Biodiversidad y Biologia Evolutiva, C/Catedratico Jose Beltran, 2 Paterna, Valencia 46980, Spain

e-mail: j.manuel.garcia@uv.es; Alfredo Quiñones-Hinojosa, Brain Tumor Stem Cell Laboratory, Department of Neurosurgery, Johns Hopkins University, 1550 Orleans St., CRB-II, Room 247, Baltimore, MD 21201, USA

e-mail: aquinon2@jhmi.edu

\section{INTRODUCTION}

Neurogenesis persists in the subventricular zone (SVZ) of the lateral ventricles throughout life. SVZ astrocytes continuously proliferate and give rise to intermediate progenitor cells, which then differentiate into neuroblasts forming large chains ensheathed by gliotubes of astrocytes (Doetsch et al., 1997; Ponti et al., 2013). These migratory structures emerge from the SVZ and coalesce into the rostral migratory stream (RMS) that ends in the olfactory bulb (OB) (Lois et al., 1996; Peretto et al., 1997; Alvarez-Buylla and Garcia-Verdugo, 2002). Thus, neuroblasts migrate tangentially from the SVZ and incorporate into the OB. Neuroblasts in the RMS retain their ability to proliferate (Smith and Luskin, 1998; Poon et al., 2010), but once they reach the OB, neuroblasts begin radial migration and mature into interneurons that integrate in preexisting functional circuits (Lois and Alvarez-Buylla, 1994; Luskin et al., 1997; Carleton et al., 2003; Imayoshi et al., 2008; Kelsch et al., 2010; Lazarini and Lledo, 2011). Although most SVZ precursor cells generate neuroblasts to support OB neurogenesis, a small subpopulation of precursors gives rise to cells in the oligodendroglial lineage, which are able to migrate toward the corpus callosum, striatum, or septum to differentiate into myelinating oligodendrocytes (Nait-Oumesmar et al., 1999; Menn et al., 2006; Gonzalez-Perez et al., 2009; Gonzalez-Perez and Alvarez-Buylla, 2011; Capilla-Gonzalez et al., in press).

During aging, the proliferative potential of the rodent SVZ decreases due to a partial depletion of neural precursor cells, with a subsequent disruption of OB neurogenesis (Maslov et al., 2004; Luo et al., 2006; Molofsky et al., 2006; Bouab et al., 2011; Conover and Shook, 2011; McGinn et al., 2012). Similarly, the human SVZ maintains its proliferative and neurogenic potential in adult life but it is drastically decreased when compared to fetal and pediatric stages (Sanai et al., 2004; Quinones-Hinojosa et al., 2006; Guerrero-Cazares et al., 2011; Sanai et al., 2011). However, the effects of aging on the genesis of new cells have mostly been studied at the SVZ level with little emphasis on the migratory pathway that the SVZ-derived cells follow to reach the OB (Bouab et al., 2011; Shook et al., 2012). Here, we investigate the age-related changes occurring across the RMS of mice. We demonstrate that this migratory pathway is deeply altered during aging and tends to disappear, resulting in a disruption of the $\mathrm{OB}$ neurogenesis. Interestingly, we found that the production of oligodendrocytes in the SVZ-OB system is not compromised by aging. Our study provides a better interpretation of the neurogenesis decline occurring in the aged brain, which could help to understand neurological disorders associated with senescence.

\section{RESULTS}

\section{THE RMS CYTOARCHITECTURE IS DISRUPTED BY AGING}

Consistent with previous studies (Luo et al., 2006; Bouab et al., 2011), the SVZ of mice showed a loss of cells during aging, particularly in the population of neuroblasts forming migratory chains (Figure S1). To evaluate if those effects from aging were 
also present in the RMS, sagittal sections of the brain were first stained with DAPI nuclear dye. We observed that the population of cells that form the RMS connecting the SVZ with the OB was diminished in the aged brain (Figures 1A,B and Figure S2). The astrocytic and neuroblast populations within the RMS were examined using the glial fibrillary acidic protein (GFAP) and doublecortin (DCX) markers, respectively. The RMS of aged mice preserved GFAP + cells that were stained more intensively than those from young mice (Figures $\mathbf{1 C}, \mathbf{D}$ ). In contrast, the expression of DCX was severely reduced during aging (Figures 1E,F). This data indicates that the aged brain maintains the astrocytes that constitute gliotubes in the young brain, but it does not preserve chains of migrating neuroblasts.

To investigate these findings further we used transmission electron microscopy. The analysis of RMS coronal sections revealed a notable loss of cells during aging, which resulted in a significant decrease of the area occupied by the RMS compared to young animals (Young $1217.7 \mu \mathrm{m}^{2}$ vs. Aged $218.7 \mu \mathrm{m}^{2}, p=$ 0.003) (Figures 2A-C). Remaining cells in the aged RMS were found to form small groups of cells that appeared isolated. Unlike the young mice, occasional cells were found in the intrabulbar part of the anterior commissure of the aged brain, where axons are located (Figure 2C). At higher magnifications, we detected that the reduction in the area occupied by the RMS was primarily due to a loss of migrating neuroblasts (Figures 2D-G). We did not observe ultrastructural differences in the remaining neuroblasts of the aged RMS compared to those from young mice. However, we found abundant dense bodies in the cytosol of astrocytes and frequent microglial cells close to the RMS in the aged brain (Figure S3).

\section{PROLIFERATIVE CELLS WITHIN THE RMS DECREASE IN THE AGED BRAIN}

To study the proliferative capacity of remaining cells in the aged RMS, animals received a single dose of 5-bromo-2-deoxyuridine (BrdU) $2 \mathrm{~h}$ before sacrifice. We observed an $83 \%$ reduction in the number of BrdU+ cells per section in the RMS of aged mice (Young $23.6 \pm 0.4$ cells vs. Aged $4 \pm 0.8$ cells, $p<0.001$ ) (Figure 3A). These proliferative cells were found in small groups of cells that were preserved in the aged RMS. Given that BrdU is only incorporated by cells in S-phase, we also used the proliferation marker Ki67 that is present during all active phases of the cell cycle (G1, S, G2, and mitosis). Consistently, we observed frequent Ki67+ cells in the young RMS, while they were occasional in aged mice ( $n=3$ in all groups), supporting the results from the BrdU assay (Figures 3B,C). To determine the identity of these proliferative cells, we performed double immunostaining against Ki67-GFAP or Ki67-DCX. In the aged RMS, some proliferative cells were found to express GFAP (Figure 3B and Figure S4), however, proliferating DCX+ cells were not detected (Figure 3C). In addition, to evaluate if proliferative cells were from the oligodendroglial lineage, we used

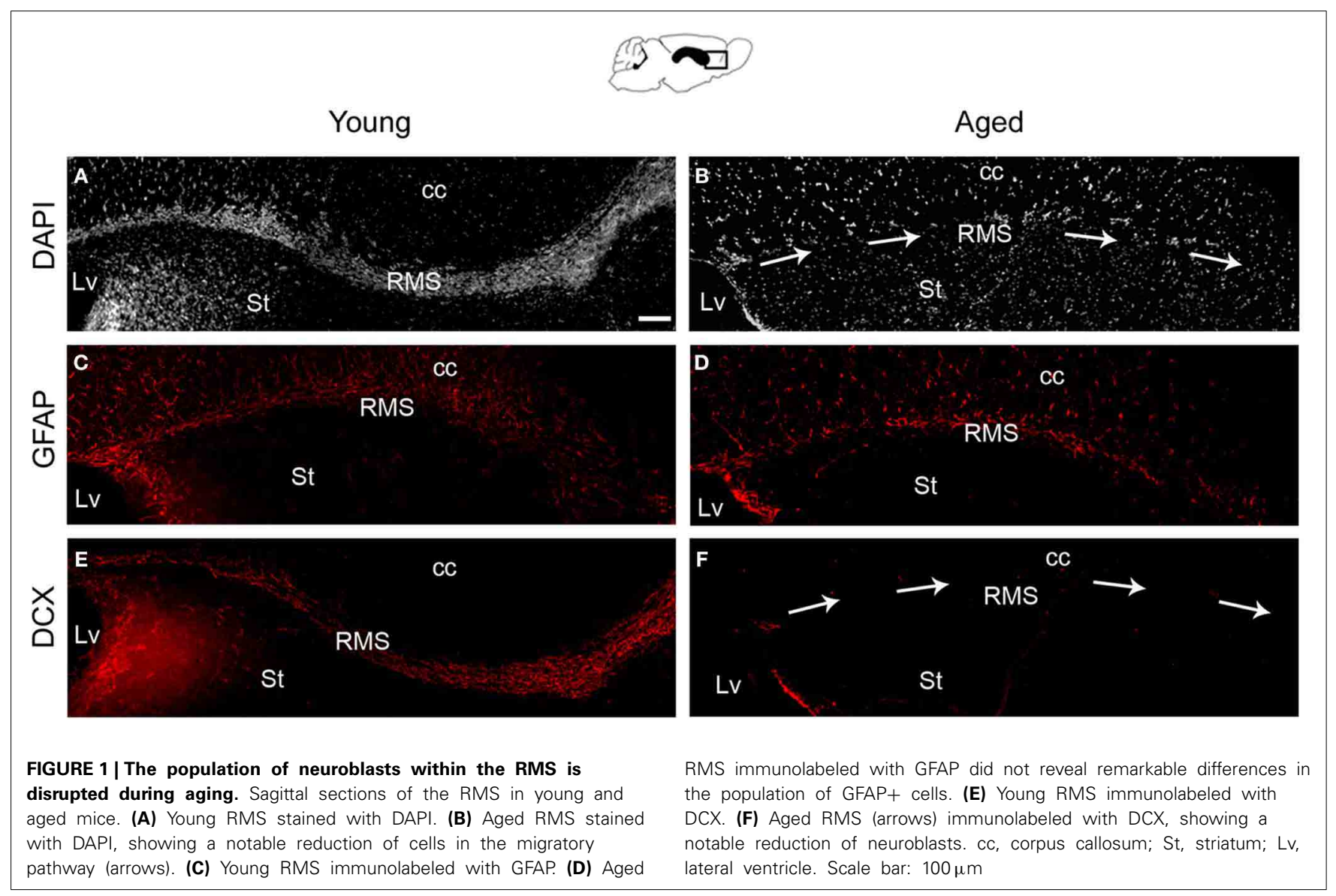




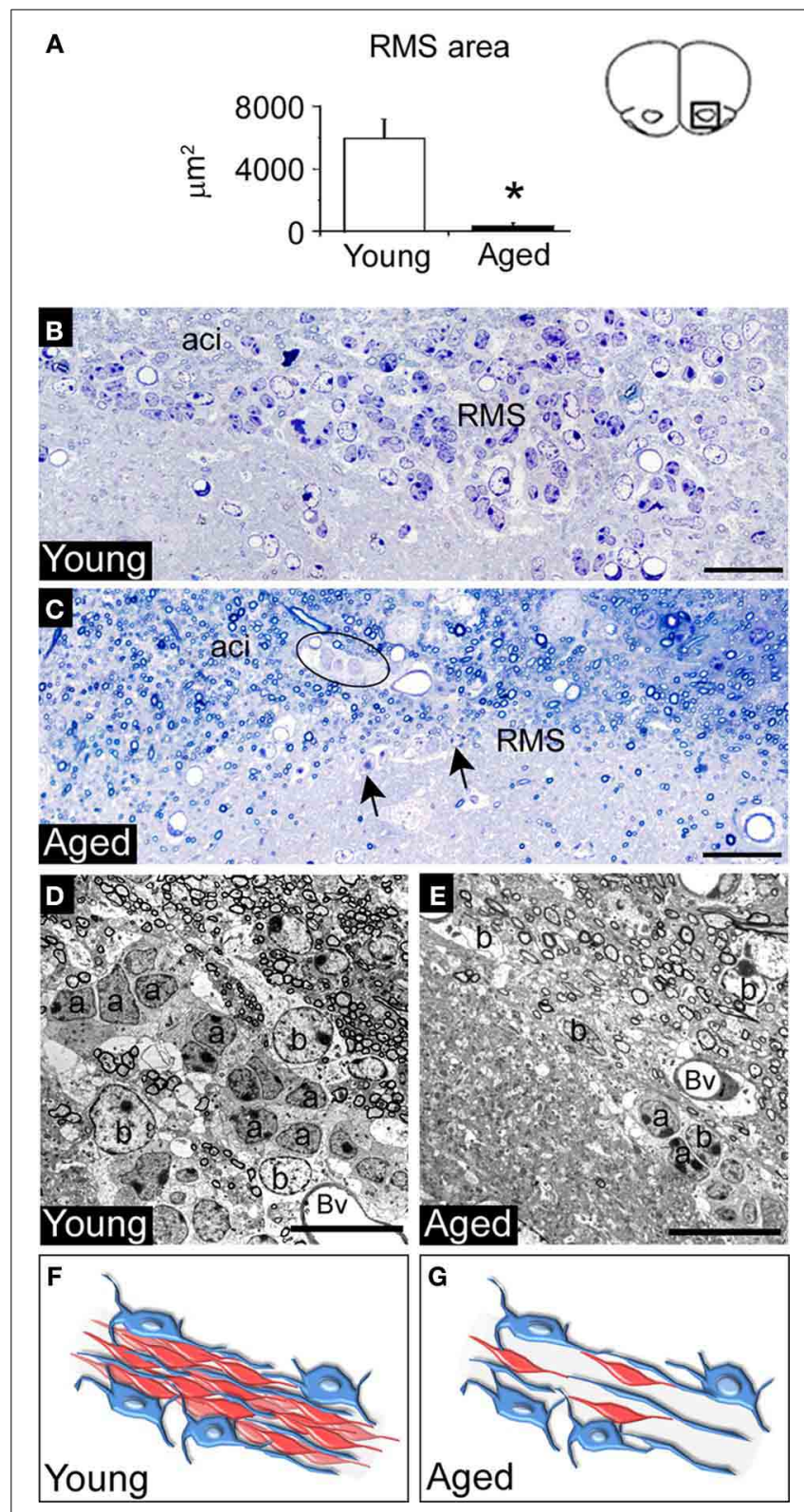

FIGURE 2 | Cytoarchitecture of aged RMS reveals a loss of migrating neuroblasts into the gliotubes. Analysis of the RMS by using light and electron microscopy. (A) Bar graph depicting a significant reduction of the area occupied by the RMS in aged mice. (B) Semithin section of the young RMS showed multiples chains of neuroblasts. (C) Semithin section of the aged RMS showed a notable loss of migratory chains, but dispersed cells remained (arrows). Note the presence of groups of neuroblasts and astrocytes within the intrabulbar part of the anterior commissure (delineated). (D) Electron microscopy image of a young RMS showing a detail of the neuroblasts chains surrounded by astrocytic gliotubes. (E) Electron microscopy image showing a detail of the aged RMS, where neuroblasts were severely reduced. (F) Schematic representation of the RMS cytoarchitecture in young mice. Chains of neuroblasts (red) migrating through gliotubes, which were formed by astrocytes (blue). (G) Schematic representation of the RMS cytoarchitecture in aged mice. Note the loss of neuroblast migrating through the gliotubes. a, neuroblast; aci, intrabulbar part of the anterior commissure; $b$, astrocyte; $B v$, blood vessel. Scale bar: $\mathbf{B}, \mathbf{C}=20 \mu \mathrm{m}, \mathbf{D}, \mathbf{E}=10 \mu \mathrm{m} .{ }^{*} p<0.01$. the transcription factor Olig2. Surprisingly, we found that both groups of animals presented an equal number of BrdU/Olig2+ cells per section (Young $1.01 \pm 0.5$ cells vs. Aged $0.8 \pm 0.2$ cells, $p=0.692$ ). Given that the overall number of BrdU+ cells declines over time, there was a resulting increase in the proportion of BrdU+ cells that expressed the Olig2 marker in the aged RMS (Young $3.5 \pm 1.9 \%$ vs. Aged $16.5 \pm 4.7 \%, p=$ 0.0117) (Figures 4A-D). These findings suggest that remaining proliferative cells in the aged RMS could be supporting oligodendrogenesis.

\section{NEWLY GENERATED CELLS IN THE AGED RMS BECOME OLIGODENDROCYTES}

In order to evaluate the proliferative potential of the RMS cells in a longer period of time and to determine the fate of the newly generated cells by ultrastructural analysis, a group of mice was injected with tritiated thymidine $\left({ }^{3} \mathrm{H}-\mathrm{Thy}, 1\right.$ dose/day) over a 10-day period and euthanized after 6 weeks (Figure 5A). The ${ }^{3} \mathrm{H}$-Thy+ cells found in the aged RMS displayed irregular contours and light cytoplasm with few intermediate filaments. Their nuclei were fusiform and contained dense, peripherallydistributed chromatin. These ${ }^{3} \mathrm{H}$-Thy+ cells had ultrastructural features bearing a resemblance to astrocytes and oligodendrocytes (Figure 5B). We also detected ${ }^{3} \mathrm{H}$-Thy+ oligodendrocytes displaying a smooth contour, round nucleus, and dark cytoplasm that contained short cisternae of rough endoplasmic reticulum and an absence of intermediate filaments (Figure 5C). The lack of dense bodies in the cytoplasm of these cells discarded the possibility of them being microglia cells. Neuroblasts labeled with ${ }^{3} \mathrm{H}$-Thy were not detected in any group, likely due to the fact that these cells had already migrated to the $\mathrm{OB}$ at the time of euthanasia. Together, these findings support the hypothesis that the incorporation of neuroblasts into the $\mathrm{OB}$ is impaired during aging, while oligodendrogenesis is preserved.

\section{NEWLY GENERATED CELLS IN THE AGED OB SUPPORT THE OLIGODENDROGLIAL LINEAGE}

To evaluate if neurogenesis in the $\mathrm{OB}$ was disrupted in the aged brain, animals were injected with 4 doses of BrdU, each dose injected with a $2 \mathrm{~h}$ interval, and euthanized after 30 days (Figure 6A). Quantitative analysis of $\mathrm{OB}$ coronal sections showed a significant decrease of BrdU+ cells in the aged group (Young $87.31 \pm 7.84$ cells vs. Aged $5.31 \pm 0.33$ cells, $p<0.001$; Figure 6B). In accordance, a decrease in the neuroblast population was observed in the aged $\mathrm{OB}$, which was more pronounced in the medial region (Figure S5). To verify if newly generated cells in the $\mathrm{OB}$ were differentiating into mature neurons, we performed a double immunostaining against BrdU and NeuN markers. The number of BrdU/NeuN+ cells per section was significantly reduced in aged mice (Young $75.6 \pm 13.01$ cells vs. Aged $3.5 \pm 0.3$ cells, $p=0.01$ ), while the percentage of BrdU+ cells that expressed NeuN did not differ across the two experimental groups (Young $90.12 \pm 2.5 \%$ vs. Aged $83.7 \pm 2.9 \%, p=$ 0.228 ). Next, the production of new cells from the oligodendroglial lineage was evaluated using the Olig2 marker. Contrarily to the decrease in neurogenesis, aged mice displayed an increase 


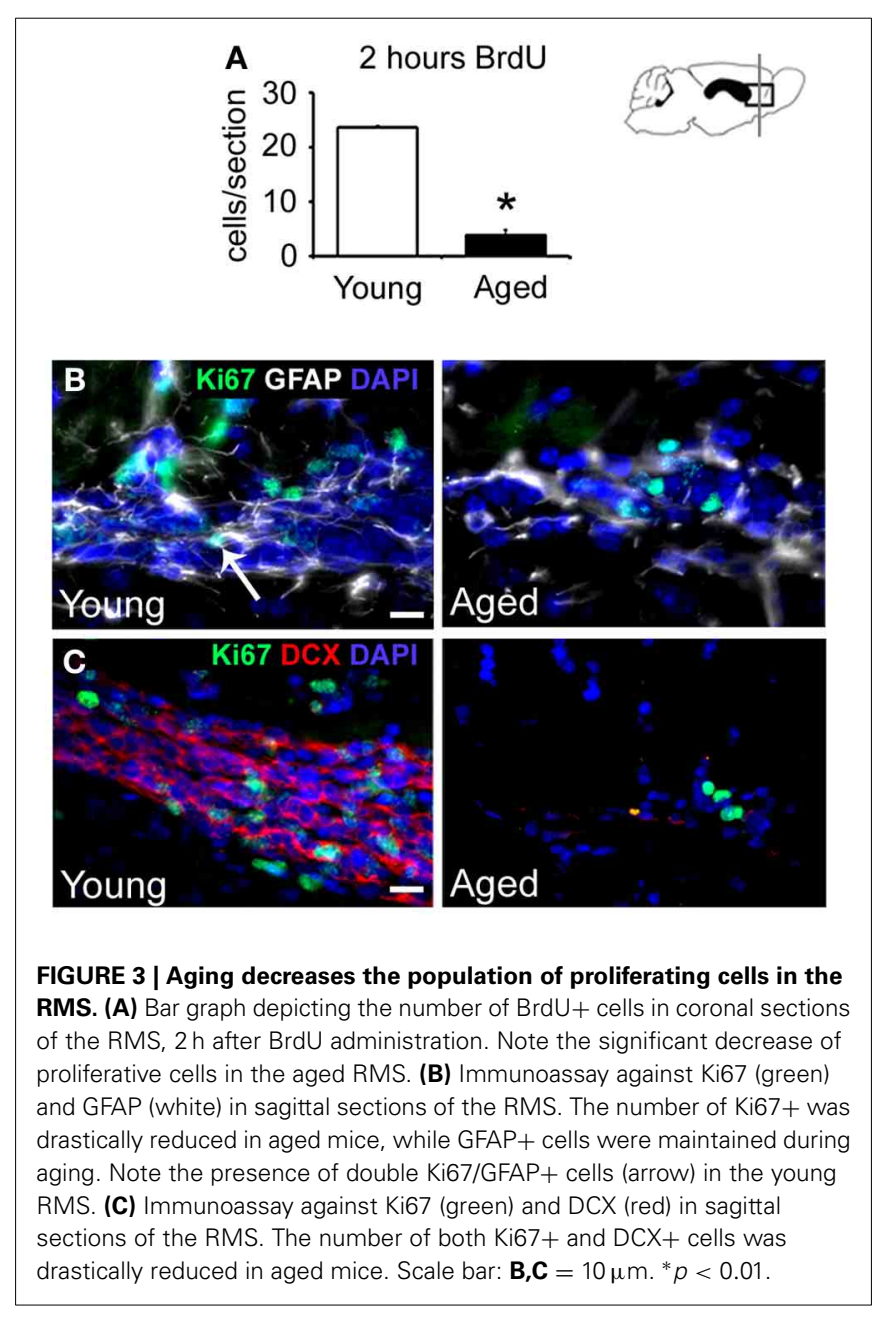

in the percentage of cells that co-expressed BrdU and Olig2 markers (Young $3.5 \pm 1.1 \%$ vs. Aged $42.7 \pm 0.7 \%, p<0.001$ ), but did not show a difference in the number of BrdU/Olig2+ cells (Young $2.7 \pm 0.6$ cells vs. Aged $2.4 \pm 0.2$ cells, $p=0.675$ ) (Figures 6C-F). The generation of new oligodendroglial cells was also examined in the corpus callosum, striatum, and SVZ of the aged mice, finding a consistent increase in the proportion of cells co-expressing BrdU and Olig2 in the SVZ (Figure S6). Interestingly, the aged $\mathrm{OB}$ showed occasional cells co-expressing BrdU, Olig2, and NeuN markers (Figure 6G). Despite the reduction in neurogenesis with aging, these results suggest that the production of oligodendrocytes is maintained across the aged SVZ-OB system.

In order to test the possibility that the new cells found in the $\mathrm{OB}$ were endogenously generated from local progenitors (Gritti et al., 2002), we examined the OB of animals that received a single dose of $\mathrm{BrdU}$ and were euthanized $2 \mathrm{~h}$ later. Immunostaining against BrdU revealed that proliferation was significantly decreased in the aged $\mathrm{OB}$ (Young $21.1 \pm 4.6$ cells vs. Aged $5.1 \pm 0.4$ cells, $p<0.001$ ). This reduction of proliferative cells was more pronounced in the medial region of the $\mathrm{OB}$, where migrating neuroblasts arrive. Interestingly, proliferative cells were found to express Olig2 in the young OB, but not in the aged OB
(Figure S7). These results suggest that the new oligodendroglial cells within the aged $\mathrm{OB}$ were not originated from local progenitors. Nonetheless, more experiments would be required to conclusively study the origin of the new oligodendroglial cells.

\section{DISCUSSION}

During aging, the SVZ undergoes a severe decline in its proliferative capacity which subsequently affects neurogenesis in the OB (Maslov et al., 2004; Luo et al., 2006; Bouab et al., 2011; McGinn et al., 2012). However, the age-related changes induced in the migratory pathway that the newly generated cells follow had not been completely described. In this study we present important findings on the effects of aging across the SVZ-OB system. We demonstrated that proliferation declines at the RMS and OB levels during aging, similar to the SVZ. We observed a decrease in the number of neuroblasts migrating across the RMS and an altered cellular organization of this migratory pathway. Finally, while we confirmed an $\mathrm{OB}$ neurogenesis decline with aging, oligodendrogenesis across the RMS was surprisingly not compromised.

Newly generated cells in the SVZ migrate a long distance through the RMS before reaching the OB, where they differentiate into interneurons to replace old cells (Lois and Alvarez-Buylla, 1994). The SVZ maintains this neurogenic capacity throughout life, but the number of cells that ultimately integrate into the OB decrease over time (Bouab et al., 2011; Shook et al., 2012). Consistent with these findings, we described a remarkable depletion of the migratory chains of neuroblasts in the SVZ during senescence, which was mimicked in the RMS. While the gliotubes of astrocytic cells were maintained in the aged brain, the number of migrating neuroblasts was drastically reduced. Subsequently, we found a decrease of newly generated cells in the aged $\mathrm{OB}$, in accordance with previous publications (Bouab et al., 2011; Shook et al., 2012). These effects on $O B$ neurogenesis could be a direct consequence of altering the SVZ niche. Prior studies from our group support this hypothesis as we previously demonstrated that the disruption of the SVZ by exposure to N-ethyl-N-nitrosourea leads to an impairment in the incorporation of new cells into the OB (Capilla-Gonzalez et al., 2012). Similarly, the radiation impact on the SVZ neurogenic niche interrupted neuroblast migration to the OB (Lazarini et al., 2009; Achanta et al., 2012). Another explanation for $\mathrm{OB}$ neurogenesis decline is that aging could impair the migratory capacity of neuroblasts, however, a recent publication suggests that the capacity of neuroblasts to exit the SVZ and reach the OB is not affected by age (Mobley et al., 2013). Based on these reports, we consider that SVZ-derived cells are able to migrate in the aged brain, but the number of cells that finally incorporate into the $\mathrm{OB}$ is drastically reduced due to the age-related effects on the SVZ niche.

Contrary to the decline in neurogenesis during senescence, we demonstrated, for the first time, that the production of oligodendroglial cells is maintained in the aged SVZ-OB system. An increase in oligodendrocyte-generation has been observed in other regions of the central nervous system, such as the spinal cord and neocortex of rodents (Levison et al., 1999; Lasiene et al., 2009), or the fornix of monkeys (Peters et al., 2010). Concurrent with these reports, a more recent study indicate that 


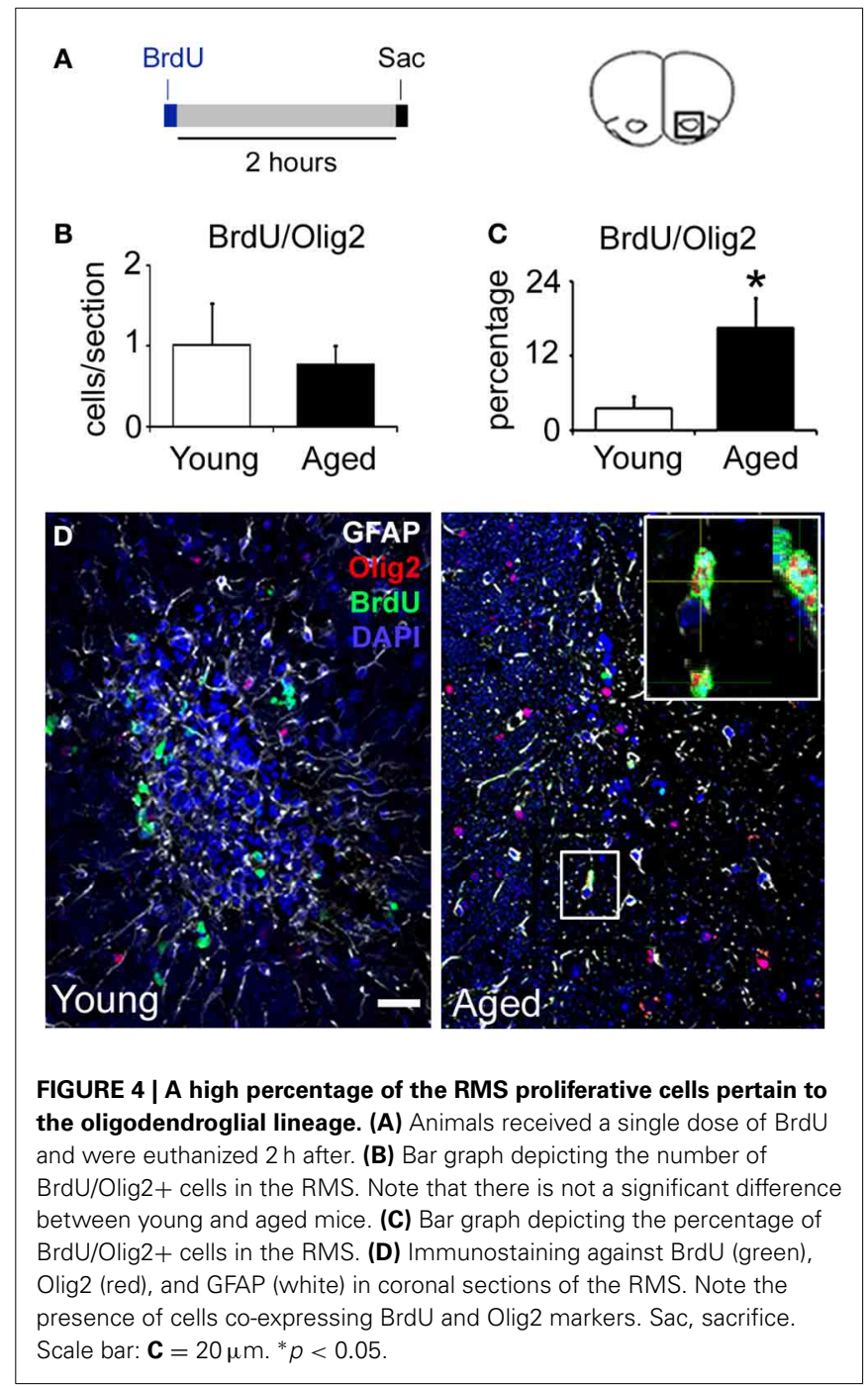

NSCs, derived from young and middle-aged SVZ, present similar ability to produce oligodendrocytes in vitro, when they were differentiated in absence of exogenous growth factors (Bouab et al., 2011). In our study, we found that the capacity of the SVZ to produce Olig2 + cells in vivo is not diminished by aging. The maintained SVZ ability to produce Olig2 + cells in the aged brain could subsequently help to preserve the oligodendrogenesis in the RMS-OB. This would require that a group of SVZ-derived cells become oligodendrocytes instead of differentiating into neurons. This idea is supported by previous reports showing that DCX + cells from the SVZ can be redirected from neuronal to glial fates following a demyelination process, and generate new oligodendrocytes in the corpus callosum (Jablonska et al., 2010). Another possible explanation for the maintenance of the oligodendrogenesis in the aged brain is that local stem cells within the $\mathrm{OB}$ are contributing to the production of oligodendroglial cells (Gritti et al., 2002; Rivers et al., 2008). In fact, stem cells isolated from the OB were found to produce more oligodendrocytes in vitro than those from the SVZ (Gritti et al., 2002). On the other hand, it could be possible that those local precursors within the OB may support neurogenesis to serve as a compensatory mechanism for the loss of newly arriving neuroblasts from the SVZ. Indeed, it has been described that oligodendrocyte progenitors in the $\mathrm{OB}$ are also able to produce new neurons in transgenic mice, after the blockage of the Platelet-Derived Growth Factor Receptor-alpha (Rivers et al., 2008). In accordance with this finding, we observed cells co-expressing BrdU, $\mathrm{NeuN}$, and Olig2 markers in the aged OB. However, the reduced number of proliferative cells detected in the OB of aged mice conflicts with the possibility that most newly generated cells, either neurons or oligodendrocytes, were produced from local precursors instead of being SVZ-derived. These modifications in cell production may respond to age-related changes in cell signaling pathways. For instance, the balance between neurogenesis and gliogenesis in the SVZ niche is controlled by the BMP and noggin signaling (Lim et al., 2000; Mekki-Dauriac et al., 2002; Bilican et al., 2008). SVZ astrocytes express BMP inducing gliogenesis, while ependymal cells express noggin that promotes neurogenesis. Since the SVZ niche is disrupted during aging (Bouab et al., 2011; Shook et al., 2012), the BMP-noggin balance could be modified and contribute to the neurogenesis decline and favor oligodendrogenesis. Further studies are required to fully understand the mechanisms associated to the age-related changes described here.

Although the existence of the RMS in the adult human brain remains highly controversial (Sanai et al., 2004, 2007; Curtis et al., 2007; Kam et al., 2009; Wang et al., 2011), the presence of neural stem cells within the SVZ is widely accepted (Sanai et al., 2004; Quinones-Hinojosa et al., 2006). Nevertheless, the function of the newly generated cells in the human brain is currently unknown. A recent publication demonstrated that the postnatal production of new neurons in humans is minimal, while there is a continuous turnover of non-neuronal cells, which could contribute to the production of oligodendrocytes (Bergmann et al., 2012). Hence, the neurogenic system of aged mice becomes a better model for comparisons with adult human beings than the neurogenic system from young rodents. The maintained oligodendrogenesis provides new insight into the relevance of the oligodendrocytes throughout life, which could be a response to myelin damaged during aging (Nait-Oumesmar et al., 1999; Jablonska et al., 2010; Gonzalez-Perez and Alvarez-Buylla, 2011; Capilla-Gonzalez et al., in press). Moreover, oligodendrogenesis could be beneficial for the proper function of the remaining neurons in the aged brain. All of these possible functions could be crucial to the survival and maturation of newly generated oligodendrocytes.

In conclusion, we have demonstrated that the decrease of SVZ proliferation during aging is mimicked in the RMS-OB system. Neuroblast migratory chains are severely disrupted across the whole RMS of aged mice, consistent with OB neurogenesis impairment. Furthermore, oligodendrogenesis is maintained in the SVZ-OB system of the aged brain, but the origin of these new cells is still unknown. These findings provide new insight into the events occurring during aging on the genesis of new cells. Modifying the source and subsequent fate of these newly generated cells in the aged brain could serve as the foundation for new therapeutic strategies for brain disorders associated with senescence. 


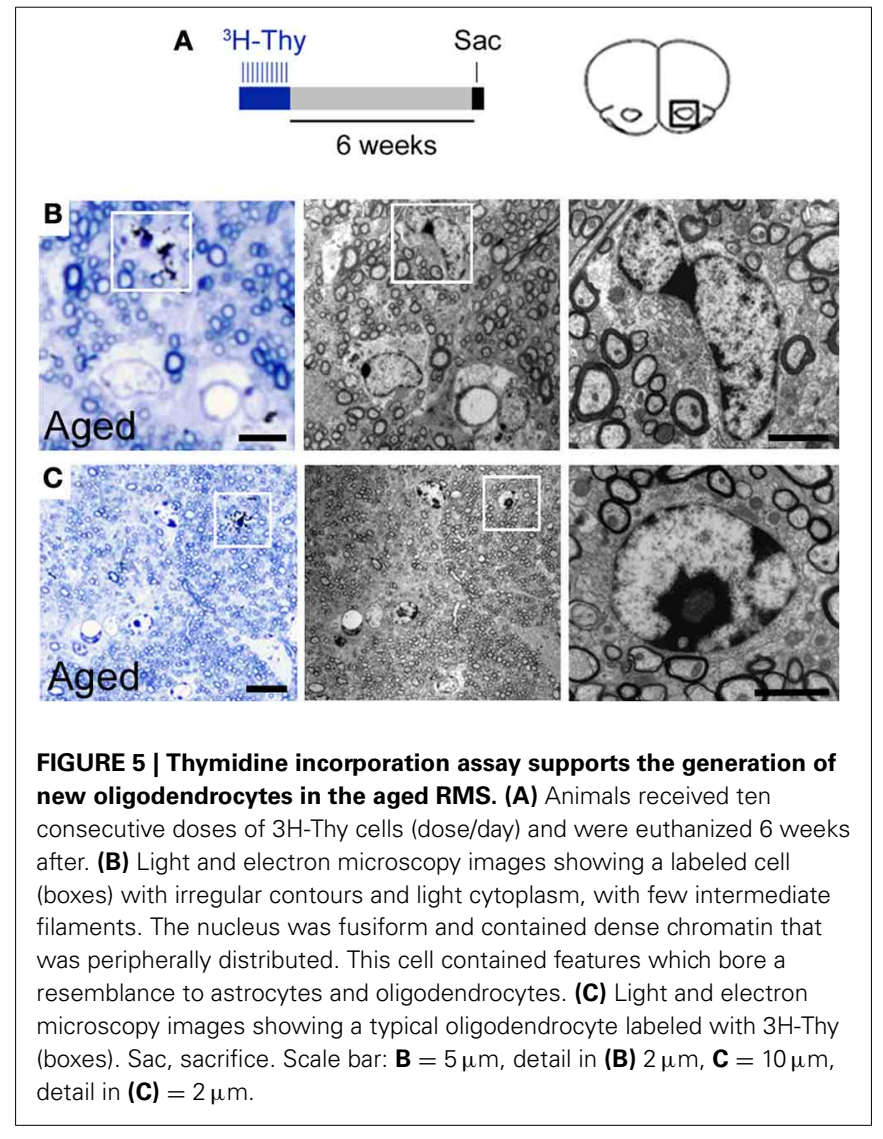

\section{EXPERIMENTAL PROCEDURES ANIMALS}

The animals used were 2 and 24-month-old C57BL/6 male mice $\left(n_{\text {young }}=20, n_{\text {aged }}=22\right)$ from National Institute on Aging (Baltimore, MD, USA) and Charles River Laboratory (Barcelona, Spain). Animals were housed under a 12-h light/dark cycle with food and water available ad libitum. All animal procedures were performed according to the European Communities Council (86/609/EEC) guidelines and approved by the Johns Hopkins Animal Care and Use Committee and followed standard animal care and use protocols.

\section{ADMINISTRATION OF 5-BROMO-2-DEOXYURIDINE}

5-bromo-2-deoxyuridine (BrdU, Sigma Aldrich, Dorset, UK) is an exogenous marker, which is incorporated into the newly synthesized DNA of replicating cells, during the S phase. To study the proliferation, animals received a single intraperitoneal injection of $\mathrm{BrdU}(50 \mathrm{mg} / \mathrm{Kg}$ b.wt.) and were euthanized $2 \mathrm{~h}$ after ( $n_{\text {young }}=4, n_{\text {aged }}=6$ ). To assess cell migration, animals received 4 intraperitoneal injections of BrdU, separated by $2 \mathrm{~h}$, and were euthanized 30 days later $\left(n_{\text {young }}=3, n_{\text {aged }}=3\right)$.

\section{TRITIATED THYMIDINE ADMINISTRATION}

For ultrastructural identification of the proliferative cells and newly generated cells, animals received a single daily dose of $1.67 \mu \mathrm{l} / \mathrm{g}$ b.wt. of $1 \mathrm{mCi}$ tritiated thymidine $\left({ }^{3} \mathrm{H}\right.$-Thy; specific activity $5 \mathrm{Ci} / \mathrm{mmol}$; Amersham Biosciences, Uppsala, Sweden), for 10 consecutive days, and were euthanized 6 weeks after the last injection $\left(n_{\text {young }}=4, n_{\text {aged }}=4\right)$.

\section{BRAIN TISSUE FIXATION}

Animals were anesthetized by an intraperitoneal injection of 2:1 ketamine/xylazine ( $5 \mu \mathrm{l} / \mathrm{g}$ of weight) and subjected to an intracardiac perfusion using a peristaltic pump. As fixative, we used $4 \%$ paraformaldehyde for immunohistochemistry, or $2 \%$ paraformaldehyde and 2.5\% glutaraldehyde for electron microscopy. Prior brain dissection, heads were removed and post-fixed in the same fixative overnight.

\section{IMMUNOHISTOCHEMISTRY}

After post-fixation, brains were washed in $0.1 \mathrm{M} \mathrm{PB}$ and cut into serial $10 \mu \mathrm{m}$ thick coronal $\left(n_{\text {young }}=7, n_{\text {aged }}=9\right)$ or sagittal ( $n_{\text {young }}=3, n_{\text {aged }}=3$ ) sections using a cryostat (Leica, CM 1900). One series (5-8 sections) from each animal was used in each immunostaining. Sections were incubated in blocking solution for $1 \mathrm{~h}$ at room temperature, followed by overnight incubation at $4^{\circ} \mathrm{C}$ with primary antibodies (see Table S1). Then, sections were washed and incubated with the appropriate secondary antibodies conjugated with either biotin or fluorophores. After the secondary biotinylated antibody, sections were incubated with ABC Elite complex (Vector, Burlingame, CA, USA) and treated with diaminobenzidine (DAB, $0.05 \%$; Sigma Aldrich). Measurement of BrdU incorporation during DNA synthesis was carried out in coronal sections by quantification of BrdU+ cells under an Eclipse E200 light microscope (Nikon, Tokyo, Japan), and were expressed as cells/section. Fluorescence samples were examined under an Olympus IX81 confocal microscope and imaged using the Olympus Fluoview software version 3.1 (Center Valley, PA, USA). Three-dimensional images were obtained using the Slidebook ${ }^{\mathrm{TM}}$ software (Intelligent Imaging Innovations, Denver, CO, USA). Quantification of BrdU double immunostaining with NeuN or Olig2 was expressed as double + cells per section and as percentage $(100 \times$ BrdU-NeuN + cells/total BrdU+ cells and $100 \times$ BrdU-Olig2 + cells/total BrdU+ cells).

\section{TRANSMISSION ELECTRON MICROSCOPY}

Post-fixated brains were washed in $0.1 \mathrm{M}$ phosphate buffer (PB; pH 7.4), cut into $200 \mu \mathrm{m}$ sections with a VT $1000 \mathrm{M}$ vibratome (Leica, Wetzlar, Germany) and treated with $2 \%$ osmium tetraoxide in $0.1 \mathrm{M} \mathrm{PB}$ for $2 \mathrm{~h}$. Then sections were rinsed, dehydrated through increasing ethanol solutions and stained in 2\% uranyl acetate at 70\% ethanol. Following dehydration, slices were embedded in araldite (Durcupan, Fluka BioChemika, Ronkokoma, NY, USA). To study cell organization of the RMS, we cut serial $1.5 \mu \mathrm{m}$ semithin sections with a diamond knife and stained them with $1 \%$ toluidine blue. To identify individual cell types, $60-70 \mathrm{~nm}$ ultrathin sections were cut with a diamond knife, stained with lead citrate, and examined under a Spirit transmission electron microscope (FEI Tecnai, Hillsboro, OR, USA). Changes in the area of the RMS were determined by measuring the area occupied by the RMS in semithin sections of 3 different levels per animal ( $n_{\text {young }}=6, n_{\text {aged }}=6$ ), using light microscopy. The analysis was 


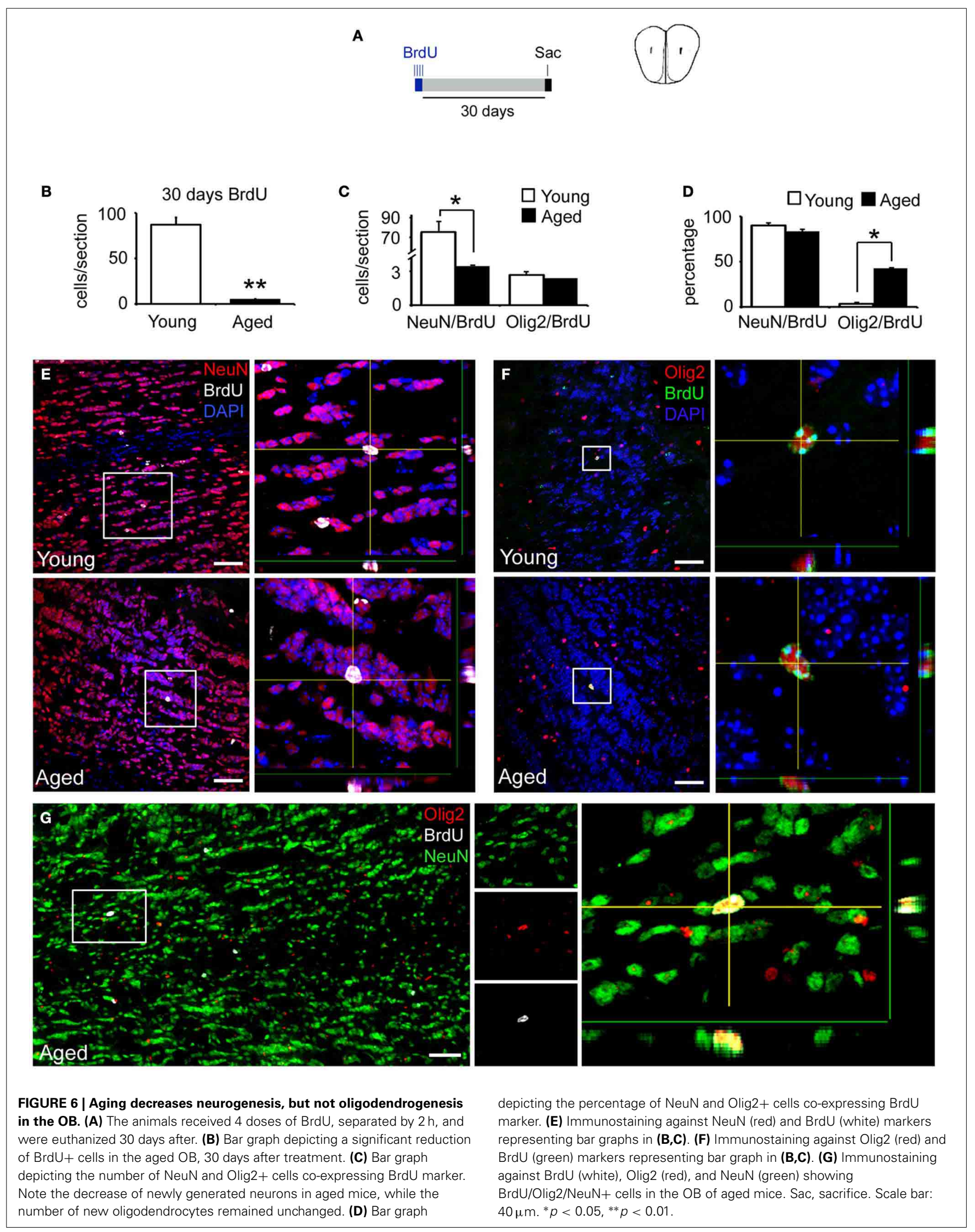


performed with Image Tool software (Evans Technology, Roswell, GA, USA).

\section{TRITIATED THYMIDINE AUTORADIOGRAPHY}

Brains treated with ${ }^{3} \mathrm{H}$-Thy were processed for transmission electron microscopy as described above. Subsequently, semithin sections were dipped in LM-1 hypercoat emulsion (Amersham Biosciences), dried in the dark, and stored at $4^{\circ} \mathrm{C}$ for a month (Doetsch et al., 1997). Autoradiography was developed using standard methods and counterstained with $1 \%$ toluidine blue. Selected semithin sections, with a total of 40 labeled cells, were processed for ultrathin sections to be analyzed using electron microscopy.

\section{STATISTICAL ANALYSIS}

Data were expressed as mean \pm SEM. After testing for normal distribution with Shapiro-Wilke Test, a Student's $t$-test was performed using SigmaPlot 11.0 software (Jandel Scientific, San Rafael, CA, USA). For samples that were not normally distributed, the non-parametric Mann Whitney $U$-Test was used. Differences were considered significant at a $p$-value lower than 0.05 .

\section{AUTHOR CONTRIBUTIONS}

Vivian Capilla-Gonzalez, collection and assembly of data, concept and design, data analysis and interpretation, manuscript writing,

\section{REFERENCES}

Achanta, P., Capilla-Gonzalez, V., Purger, D., Reyes, J., Sailor, K., Song, H., et al. (2012). Subventricular zone localized irradiation affects the generation of proliferating neural precursor cells and the migration of neuroblasts. Stem Cells 30, 2548-2560. doi: 10.1002/stem.1214

Alvarez-Buylla, A., and GarciaVerdugo, J. M. (2002). Neurogenesis in adult subventricular zone. J. Neurosci. 22, 629-634.

Bergmann, O., Liebl, J., Bernard, S., Alkass, K., Yeung, M. S., Steier, P., et al. (2012). The age of olfactory bulb neurons in humans. Neuron 74, 634-639. doi: 10.1016/j.neuron.2012.03.030

Bilican, B., Fiore-Heriche, C., Compston, A., Allen, N. D., and Chandran, S. (2008). Induction of Olig2 precursors by FGF involves BMP signalling blockade at the Smad level. PLoS ONE 3:e2863. doi: 10.1371/journal.pone.0002863

Bouab, M., Paliouras, G. N., Aumont, A., Forest-Berard, K., and Fernandes, K. J. (2011). Aging of the subventricular zone neural stem cell niche: evidence for quiescence-associated changes between early and mid-adulthood. Neuroscience 173, 135-149. doi: 10.1016/j.neuroscience.2010.11.032 Capilla-Gonzalez, V., Gil-Perotin, S., Ferragud, A., Bonet-Ponce,
L., Canales, J. J., and GarciaVerdugo, J. M. (2012). Exposure to N-ethyl-N-nitrosourea in adult mice alters structural and functional integrity of neurogenic sites. PLoS ONE 7:e29891. doi: 10.1371/journal.pone.0029891

Capilla-Gonzalez, V., GuerreroCazares, H., Bonsu, J. M., Gonzalez-Perez, O., Achanta, P., Wong, J., et al. (in press). The subventricular zone is able to respond to a demyelinating lesion after localized radiation. Stem Cells. doi: 10.1002/stem.1519

Carleton, A., Petreanu, L. T., Lansford, R., Alvarez-Buylla, A., and Lledo, P. M. (2003). Becoming a new neuron in the adult olfactory bulb. Nat. Neurosci. 6, 507-518. doi: 10.1038/nn 1048

Conover, J. C., and Shook, B. A. (2011). Aging of the subventricular zone neural stem cell niche. Aging Dis. 2, 49-63.

Curtis, M. A., Kam, M., Nannmark, U., Anderson, M. F., Axell, M. Z., Wikkelso, C., et al. (2007). Human neuroblasts migrate to the olfactory bulb via a lateral ventricular extension. Science 315, 1243-1249. doi: $10.1126 /$ science. 1136281

Doetsch, F., Garcia-Verdugo, J. M., and Alvarez-Buylla, A. (1997). Cellular composition and three-dimensional organization of the subventricular germinal zone in the adult

final approval of manuscript; Arantxa Cebrian-Silla and Hugo Guerrero-Cazares, collection of data, data analysis and interpretation, final approval of manuscript; Jose M. Garcia-Verdugo and Alfredo Quiñones-Hinojosa, concept and design, data analysis and interpretation, final approval of manuscript, financial support.

\section{ACKNOWLEDGMENTS}

We thank William Ruff and Samuel Klein for his proof and critical reading of the manuscript. This research was supported by the National Institutes of Health-RO1 NS070024 and the Maryland Stem Cell Research Fund (Alfredo QuiñonesHinojosa, Hugo Guerrero-Cazares), the Robert Wood Johnson Foundation (Alfredo Quiñones-Hinojosa), the Howard Hughes Medical Institute (Alfredo Quiñones-Hinojosa), the Prometeo grant GVPROMETEO-2009/011 (Jose M. Garcia-Verdugo), the Red de TerapiaCelularTerCel (RETICS) from Instituto de Salud Carlos III (Jose M. Garcia-Verdugo), and the Spanish MINECO grants (SAF2012-33683 and AP2010-4264) (Jose M. Garcia Verdugo and Arantxa Cebrian-Silla).

\section{SUPPLEMENTARY MATERIAL}

The Supplementary Material for this article can be found online at: http://www.frontiersin.org/CellularNeuroscience/10. 3389/fncel.2013.00147/abstract

mammalian brain. J. Neurosci. 17, 5046-5061.

Gonzalez-Perez, O., and Alvarez-Buylla, A. (2011). Oligodendrogenesis in the subventricular zone and the role of epidermal growth factor. Brain Res. Rev. 67, 147-156. doi: 10.1016/j. brainresrev.2011.01.001

Gonzalez-Perez, O., RomeroRodriguez, R., Soriano-Navarro, M., Garcia-Verdugo, J. M., and AlvarezBuylla, A. (2009). Epidermal growth factor induces the progeny of subventricular zone type B cells to migrate and differentiate into oligodendrocytes. Stem Cells 27, 2032-2043. doi: 10.1002/stem.119

Gritti, A., Bonfanti, L., Doetsch, F., Caille, I., Alvarez-Buylla, A., Lim, D. A., et al. (2002). Multipotent neural stem cells reside into the rostral extension and olfactory bulb of adult rodents. J. Neurosci. 22, 437-445.

Guerrero-Cazares, H., Gonzalez-Perez, O., Soriano-Navarro, M., ZamoraBerridi, G., Garcia-Verdugo, J. M., and Quinones-Hinojosa, A. (2011). Cytoarchitecture of the lateral ganglionic eminence and rostral extension of the lateral ventricle in the human fetal brain. J. Comp. Neurol. 519, 1165-1180. doi: 10.1002/cne.22566

Imayoshi, I., Sakamoto, M., Ohtsuka, T., Takao, K., Miyakawa, T., Yamaguchi, M., et al. (2008).
Roles of continuous neurogenesis in the structural and functional integrity of the adult forebrain. Nat. Neurosci. 11, 1153-1161. doi: 10.1038/nn.2185

Jablonska, B., Aguirre, A., Raymond, M., Szabo, G., Kitabatake, Y., Sailor, K. A., et al. (2010). Chordin-induced lineage plasticity of adult SVZ neuroblasts after demyelination. Nat. Neurosci. 13, 541-550. doi: 10.1038/ nn.2536

Kam, M., Curtis, M. A., McGlashan, S. R., Connor, B., Nannmark, U., and Faull, R. L. (2009). The cellular composition and morphological organization of the rostral migratory stream in the adult human brain. J. Chem. Neuroanat. 37, 196-205. doi: 10.1016/j.jchemneu. 2008.12.009

Kelsch, W., Sim, S., and Lois, C. (2010). Watching synaptogenesis in the adult brain. Annu. Rev. Neurosci. 33, 131-149. doi: 10.1146/annurevneuro-060909-153252

Lasiene, J., Matsui, A., Sawa, Y., Wong, F., and Horner, P. J. (2009). Agerelated myelin dynamics revealed by increased oligodendrogenesis and short internodes. Aging Cell 8, 201-213. doi: 10.1111/j.1474-9726. 2009.00462.x

Lazarini, F., and Lledo, P. M. (2011). Is adult neurogenesis essential for olfaction? 
Trends Neurosci. 34, 20-30. doi: 10.1016/j.tins.2010.09.006

Lazarini, F., Mouthon, M. A., Gheusi, G., De Chaumont, F., Olivo-Marin, J. C., Lamarque, S., et al. (2009). Cellular and behavioral effects of cranial irradiation of the subventricular zone in adult mice. PLoS ONE 4:e7017. doi: 10.1371/journal.pone.0007017

Levison, S. W., Young, G. M., and Goldman, J. E. (1999). Cycling cells in the adult rat neocortex preferentially generate oligodendroglia. J. Neurosci. Res. 57, 435-446. doi: $\quad 10.1002 /($ SICI) 1097-4547 (19990815) 57:4<435::AID-JNR3> 3.0.CO;2-L

Lim, D. A., Tramontin, A. D., Trevejo, J. M., Herrera, D. G., GarciaVerdugo, J. M., and Alvarez-Buylla, A. (2000). Noggin antagonizes BMP signaling to create a niche for adult neurogenesis. Neuron 28, 713-726. doi: 10.1016/S0896-6273 (00)00148-3

Lois, C., and Alvarez-Buylla, A. (1994). Long-distance neuronal migration in the adult mammalian brain. Science 264, 1145-1148. doi: $10.1126 /$ science. 8178174

Lois, C., Garcia-Verdugo, J. M., and Alvarez-Buylla, A. (1996). Chain migration of neuronal precursors. Science 271, 978-981. doi: 10.1126/science.271.5251.978

Luo, J., Daniels, S. B., Lennington, J. B., Notti, R. Q., and Conover, J. C. (2006). The aging neurogenic subventricular zone. Aging Cell 5, 139-152. doi: 10.1111/j.14749726.2006.00197.x

Luskin, M. B., Zigova, T., Soteres, B. J., and Stewart, R. R. (1997). Neuronal progenitor cells derived from the anterior subventricular zone of the neonatal rat forebrain continue to proliferate in vitro and express a neuronal phenotype. Mol. Cell. Neurosci. 8, 351-366. doi: 10.1006/mcne. 1996.0592

Maslov, A. Y., Barone, T. A., Plunkett, R. J., and Pruitt, S. C. (2004). Neural stem cell detection, characterization, and age-related changes in the subventricular zone of mice. J. Neurosci. 24, 1726-1733. doi: 10.1523/JNEUROSCI.4608-03.2004
McGinn, M. J., Colello, R. J., and Sun, D. (2012). Age-related proteomic changes in the subventricular zone and their association with neural stem/progenitor cell proliferation. J. Neurosci. Res. 90, 1159-1168. doi: 10.1002/jnr.23012

Mekki-Dauriac, S., Agius, E., Kan, P., and Cochard, P. (2002). Bone morphogenetic proteins negatively control oligodendrocyte precursor specification in the chick spinal cord. Development 129, 5117-5130.

Menn, B., Garcia-Verdugo, J. M., Yaschine, C., Gonzalez-Perez, O., Rowitch, D., and AlvarezBuylla, A. (2006). Origin of oligodendrocytes in the subventricular zone of the adult brain. J. Neurosci. 26, 7907-7918. doi: 10.1523/JNEUROSCI.1299-06.2006

Mobley, A. S., Bryant, A. K., Richard, M. B., Brann, J. H., Firestein, S. J., and Greer, C. A. (2013). Agedependent regional changes in the rostral migratory stream. Neurobiol. Aging 34, 1873-1881. doi: 10.1016/j. neurobiolaging.2013.01.015

Molofsky, A. V., Slutsky, S. G., Joseph, N. M., He, S., Pardal, R., Krishnamurthy, J., et al. (2006). Increasing p16INK4a expression decreases forebrain progenitors and neurogenesis during ageing. Nature 443, 448-452. doi: 10.1038 /nature05091

Nait-Oumesmar, B., Decker, L., Lachapelle, F., Avellana-Adalid, V., Bachelin, C., and Van Evercooren, A. B. (1999). Progenitor cells of the adult mouse subventricular zone proliferate, migrate and differentiate into oligodendrocytes after demyelination. Eur. J. Neurosci. 11, 4357-4366. doi: $\quad 10.1046 / j .1460-9568.1999$. 00873.x

Peretto, P., Merighi, A., Fasolo, A., and Bonfanti, L. (1997). Glial tubes in the rostral migratory stream of the adult rat. Brain Res. Bull. 42, 9-21. doi: 10.1016/S0361-9230 (96)00116-5

Peters, A., Sethares, C., and Moss, M. B. (2010). How the primate fornix is affected by age. J. Comp. Neurol. 518, 3962-3980. doi: 10.1002/ cne. 22434
Ponti, G., Obernier, K., Guinto, C., Jose, L., Bonfanti, L., and Alvarez-Buylla A. (2013). Cell cycle and lineage progression of neural progenitors in the ventricular-subventricular zones of adult mice. Proc. Natl. Acad. Sci. U.S.A. 110, E1045-E1054. doi 10.1073/pnas.1219563110

Poon, A., Li, Z., Wolfe, G. W., Lu, L., Williams, R. W., Hayes, N. L., et al. (2010). Identification of a Chr 11 quantitative trait locus that modulates proliferation in the rostral migratory stream of the adult mouse brain. Eur. J. Neurosci. 32, 523-537. doi: 10.1111/j.14609568.2010.07316. $\mathrm{x}$

Quinones-Hinojosa, A., Sanai, N., Soriano-Navarro, M., GonzalezPerez, O., Mirzadeh, Z., Gil-Perotin, S., et al. (2006). Cellular composition and cytoarchitecture of the adult human subventricular zone: a niche of neural stem cells. J. Comp. Neurol. 494, 415-434. doi: $10.1002 / \mathrm{cne} .20798$

Rivers, L. E., Young, K. M., Rizzi, M., Jamen, F., Psachoulia, K., Wade, A., et al. (2008). PDGFRA/NG2 glia generate myelinating oligodendrocytes and piriform projection neurons in adult mice. Nat. Neurosci. 11, 1392-1401. doi: 10.1038/nn. 2220

Sanai, N., Berger, M. S., GarciaVerdugo, J. M., and Alvarez-Buylla, A. (2007). Comment on "Human neuroblasts migrate to the olfactory bulb via a lateral ventricular extension." Science 318, 393. doi: 10.1126/science. 1145011

Sanai, N., Nguyen, T., Ihrie, R. A., Mirzadeh, Z., Tsai, H. H., Wong, M., et al. (2011). Corridors of migrating neurons in the human brain and their decline during infancy. Nature 478, 382-386. doi: 10.1038 /nature 10487

Sanai, N., Tramontin, A. D., QuinonesHinojosa, A., Barbaro, N. M., Gupta, N., Kunwar, S., et al. (2004). Unique astrocyte ribbon in adult human brain contains neural stem cells but lacks chain migration. Nature 427, 740-744. doi: 10.1038/nature02301

Shook, B. A., Manz, D. H., Peters, J. J., Kang, S., and Conover, J. C. (2012). Spatiotemporal changes to the subventricular zone stem cell pool through aging. J. Neurosci. 32, 6947-6956. doi: 10.1523/JNEUROSCI.5987-11.2012 Smith, C. M., and Luskin, M. B. (1998). Cell cycle length of olfactory bulb neuronal progenitors in the rostral migratory stream. Dev. Dyn. 213, 220-227. doi: 10.1002/(SICI)1097-0177(199810) 213:2<220::AID-AJA7>3.0.CO;2-I

Wang, C., Liu, F., Liu, Y. Y., Zhao, C. H., You, Y., Wang, L., et al. (2011). Identification and characterization of neuroblasts in the subventricular zone and rostral migratory stream of the adult human brain. Cell Res. 21, 1534-1550. doi: $10.1038 / \mathrm{cr} .2011 .83$

Conflict of Interest Statement: The authors declare that the research was conducted in the absence of any commercial or financial relationships that could be construed as a potential conflict of interest.

Received: 21 June 2013; paper pending published: 17 July 2013; accepted: 21 August 2013; published online: 11 September 2013.

Citation: Capilla-Gonzalez V, CebrianSilla A, Guerrero-Cazares H, GarciaVerdugo JM and Quinones-Hinojosa A (2013) The generation of oligodendroglial cells is preserved in the rostral migratory stream during aging. Front. Cell. Neurosci. 7:147. doi: 10.3389/fncel. 2013.00147

This article was submitted to the journal Frontiers in Cellular Neuroscience.

Copyright (C) 2013 Capilla-Gonzalez, Cebrian-Silla, Guerrero-Cazares, Garcia-Verdugo and QuinonesHinojosa. This is an open-access article distributed under the terms of the Creative Commons Attribution License (CCBY). The use, distribution or reproduction in other forums is permitted, provided the original author(s) or licensor are credited and that the original publication in this journal is cited, in accordance with accepted academic practice. No use, distribution or reproduction is permitted which does not comply with these terms. 